\title{
Consumption Patterns of Energy Drinks in Portuguese Adolescents from A City in Northern Portugal
}

\section{Padrões de Consumo de Bebidas Energéticas em Adolescentes Portugueses de Uma Cidade do Norte de Portugal}

\author{
Albino MARTINS $\triangle^{1}$, Carmo FERREIRA², Dinis SOUSA ${ }^{3}$, Sandra COSTA ${ }^{2}$ \\ Acta Med Port 2018 Apr;31(4):207-212 • https://doi.org/10.20344/amp.9403
}

\section{ABSTRACT}

Introduction: Energy drinks are youth-targeted beverages that contain high amounts of caffeine and other stimulants. A number of deleterious health effects associated with consumption of these drinks have already been reported. Despite the health concerns, energy drinks research has been sparse, especially at younger ages. The main purpose of this study was to determine the prevalence of energy drinks consumption and patterns of use among adolescents.

Materials and Methods: Cross-sectional study of students aged between $11-17$ years-old attending four public schools in Braga, cluster sampled. A self-administrated questionnaire was used to access sociodemographic data, self-reported academic performance as well as energy drinks consumption patterns, attitudes, awareness and associated symptoms.

Results: In a total of 1414 adolescents studied (mean age $15.1 \pm 1.5$ years; $53.9 \%$ were females), $56.7 \%$ reported to have used energy drinks at least once (62.5\% in males; $52.1 \%$ in females). Of those, $34 \%$ described a regular consumption (at least once a month) and $14.1 \%$ a weekly consumption. The most common reasons for energy drinks consumption were the pleasant taste (49\%), desire to increase global energy (35\%) or sports performance (33\%). On average, energy drinks users were older compared with non-users. Energy drinks consumption was associated with male gender and with self-reported worse academic performance. Approximately onethird experienced at least one symptom after consumption. In addition, $39.9 \%$ of energy drinks consumers reported mixing those with alcohol.

Discussion: Consumption of energy drinks has been increasing. The prevalence found for its consumption in this study is similar to that reported in the literature. Knowledge about motivation, general awareness of the risks or other variables related to consumption of these drinks might allow a better characterization of this behavior.

Conclusion: This study showed a high prevalence of energy drinks consumption among adolescents from a city in Northern Portugal, with self-reported symptoms after consumption and common concomitant use of alcohol.

Keywords: Adolescent; Energy Drinks; Portugal

\section{RESUMO}

Introdução: As bebidas energéticas contêm elevadas quantidades de cafeína e outros estimulantes, sendo especialmente publicitadas para jovens. Diversos efeitos nocivos associados com o seu consumo têm sido reportados. Não obstante, a investigação nesta área é escassa, em particular nos mais jovens. O objetivo primário do estudo foi determinar a prevalência e padrões de consumo de bebidas energéticas em adolescentes.

Materiais e Métodos: Estudo transversal de indivíduos entre os 11 - 17 anos, alunos em quatro escolas públicas, em Braga. Utilizou-se um questionário de autopreenchimento para obter dados sociodemográficos, rendimento escolar auto reportado, padrão de consumo de bebidas energéticas, assim como atitudes, crenças e sintomas associados.

Resultados: Dos 1414 adolescentes estudados (idade média de 15,1 $\pm 1,5$ anos; $53,9 \%$ raparigas), 56,7\% referiram consumo prévio de bebidas energéticas (62,5\% nos rapazes; $52,1 \%$ nas raparigas). Destes, $34 \%$ reportaram consumo regular, semanal em $14,1 \%$. Os motivos mais comuns para consumo foram sabor (49\%), aumento da energia (35\%) ou do rendimento desportivo (33\%). Em média, os consumidores de bebidas energéticas eram mais velhos comparativamente com não consumidores. Consumo de bebidas energéticas associou-se com género masculino e menor rendimento escolar. Cerca de um terço $(30,6 \%)$ referiu pelo menos um sintoma após o consumo. Adicionalmente, 39,9\% reportaram consumo conjunto com álcool.

Discussão: O consumo de bebidas energéticas tendo vindo a crescer. A prevalência encontrada para o seu consumo neste estudo é similar à encontrada na literatura. O conhecimento da motivação, consciencialização dos riscos ou outras variáveis relacionadas com o seu consumo poderá contribuir para uma melhor caracterização deste comportamento.

Conclusão: Demonstrou-se uma elevada prevalência de consumo de bebidas energéticas entre adolescentes de uma cidade do Norte de Portugal, sendo frequente a ocorrência de sintomas após o consumo e o uso concomitante com álcool.

Palavras-chave: Adolescente; Bebidas Energéticas; Portugal

\section{INTRODUCTION}

Energy drinks (ED) are non-alcoholic beverages rich in stimulants such as caffeine, guarana, ginseng, ginkgo biloba, taurine or L-carnitine. ${ }^{1-5}$ EDs were first introduced to the public in the United States during the late 1940s and currently comprise a market of more than 300 different brands. ${ }^{1-3,6}$ Legislation concerning ED sale to the public is very variable between countries. For example, ED sale is banned in Denmark and Turkey, while being only restricted

1. Unidade de Saúde Familiar S. Lourenço. Braga. Portugal.

2. Serviço de Pediatria. Hospital de Braga. Braga. Portugal.

3. Serviço de Pediatria. Hospital da Nossa Senhora da Oliveira. Guimarães. Portugal.

$\triangle$ Autor correspondente: Albino Martins. albinomartins.uminho@gmail.com

Recebido: 05 de julho de 2017 - Aceite: 22 de março de 2018 | Copyright @ Ordem dos Médicos 2018 
in Canada. In other countries, such as USA and Portugal, there are no restrictions for consumption including among children and adolescents. ${ }^{7}$

The specific marketing of ED to adolescents and young adults reflects the demand of these groups. ${ }^{1,3}$ As consequence, $30 \%$ to $50 \%$ of adolescents and young adults report consuming such drinks, $5 \%$ of then on a daily basis. ${ }^{3,8}$ Advertisers claim that ED are capable of increasing alertness, endurance and attention, enhance intellectual and sporting skills, mood improvement, and, in some cases, even weight loss. ${ }^{1,3,4,9,10}$

In 2013, Wilhelm and colleagues found no overall improvement in neuropsychological functioning as a consequence of ED consumption, in terms of attention and learning ability. ${ }^{6}$ The positive effects observed on cognitive performance were short-term and even so controversial and lacking scientific confirmation. ${ }^{6}$ The short-term positive effects have been attributed mostly to ED caffeine content, which ranges between 75 - $150 \mathrm{mg}$ per can. ${ }^{3,6}$ General recommendations consider a maximum intake of $100 \mathrm{mg} /$ day in adolescents. ${ }^{3}$ Although a consumption of up to 400 $\mathrm{mg}$ a day is considered safe for adults, the impact of caffeine consumption is not well known in children and adolescents. Caffeine tolerance varies among individuals and excessive use lead to detrimental health effects. ${ }^{6}$ Intoxication can occur when plasmatic levels are higher than $10 \mathrm{mg} / \mathrm{L}$, and the risk increases if consumption occurs in a short time period. ${ }^{10}$ Symptoms of intoxication include palpitations, anxiety, nausea, vomiting, insomnia, restlessness and tremors. . $^{3,11}$ Additionally, caffeine is capable of inducing tolerance and dependence and, if consumed over an extended period of time, can even lead to addiction (characterized by nervousness, irritability, tremulousness, muscle twitching, insomnia, headache and palpitations). . $, 3,4,7,12^{2}$

In light of these facts, the risk of negative effects as a consequence of ED consumption is higher in adolescents, as they are at a critical development phase. In fact, the American Academy of Paediatrics currently claims that ED should not be consumed by adolescents, as there are no proved benefits and ED lead to the risk of nervous system over stimulation. ${ }^{13}$

In children and adolescents, ingestion of ED is associated with self-reported hyperactivity and inattention symptoms, decreased reaction time, sleep disturbances and increased daytime sleepiness. ${ }^{6-8,14,15}$ Potential fatal arrhythmia, liver damage, kidney failure, respiratory disorders and psychotic episodes can also occur in healthy ED consuming adolescents. ${ }^{3,16}$ Additionally, individuals with comorbidities raise special concern, such as children with attention deficit hyperactivity disorder (who are already taking stimulants), patients with eating disorders or bearing cardiac disease, all at higher risk of experiencing negative outcomes from ED consumption. 3,7,16

An additional factor of concern is the recurrent use of ED associated with alcohol consumption (alcohol and energy drinks - AED). ${ }^{1,12,17-20}$ This combination improves the drink taste and counteracts the alcohol intoxication and sedative effects, which enhances the risk of alcohol poisoning and dependence. 1,9,19,20 AED consumers are more prone to reckless behaviour, leading to a higher risk of accidents, injuries and other substances abuse..$^{9,17,18}$

Despite the public health concern related to ED consumption, there are few studies concerning the prevalence of ED consumption, use patterns and side effects amongst a young Portuguese population. Additionally, aggressive advertisement, easy access to ED and the lack of general information and legislation makes this a relevant research issue in Portugal. The aim of our study was to determine the prevalence and pattern of ED consumption amongst adolescents in Braga. As secondary objectives, we aimed to ascertain the awareness of consumption risks, motivation for ED drinking, symptoms after consumption, as well as self-reported sleep quality and academic performance of ED users.

\section{MATERIALS AND METHODS}

Cross-sectional study of students aged between 11 17-years-old attending four public schools from Braga district in north of Portugal, cluster sampled. A self-administrated questionnaire specifically developed for the study (available in Appendix 01, Fig. S1) was applied during class and used to access sociodemographic data, self-reported academic performance was well as ED consumption patterns, attitudes, general awareness of the risks and self-reported symptoms associated with ED use.

The enrolment of participants was mediated by the teachers in class context, without the researcher's direct contact with the adolescents. Collected information was gathered on an anonymous database and written informed consent was obtained for all participants. The study was approved by the ethics committee of Hospital de Braga and the governmental entity that monitors the conduct of surveys in schools.

The socio-demographic variables recorded were age, gender and attending year at school. Body mass index was calculated from self-reported height and weight, and categorized using age and sex specific cut-offs based on WHO reference values. Sleep duration was estimated based of self-reported average sleep and awakening time during the week. A poor academic performance was defined based on self-reported mean academic grades, being that below 3 (in $7^{\text {th }}-9^{\text {th }}$ grades; grades scale 0 to 5 ) and below 10 (in $10^{\text {th }}-12^{\text {th }}$ grades; grades scale 0 to 20 ), or if any self-reported grade retention in the past two years. ED consumption was defined as ingestion of any ED in the past. Frequency and pattern of consumption were evaluated by questioning ED users "How often do you drink ED? (1 - Daily; 2 - Weekly, 3 - Monthly; 4 - Rarely)" and "In a typical drinking day, how many units of ED do you drink? $(1,2,3 ;>3)$ ". Regular ED consumption was considered if occurring at least once a month. To assess the reasons for ED consumption, individuals were asked "Why do you drink ED? (1 - Increase energy; 2 - Decrease sleep; 3 - Study better; 4 - To do sports; 5 - Because my friends do it; 6 
- Taste; 7 - Other). Self-awareness of potential ED health risk was accessed questioning "What do you think about ED use effect in your health? (1 - They are good because they increase my energy; 2 - No harm in sporadic consumption; 4 - May have some consequences for my health; 4 - No opinion)"; Adolescents were also asked if they perceived any discomfort or symptom after ED consumption ("1 Agitation or anxiety; 2 - Insomnia or trouble to sleep; 3 Accelerated heart beat; 4 - Headache; 5 - Tremors; 6 Other). For ED users, coffee consumption (number of cups a day) was registered and the use of AED was accessed by asking adolescents "Have you ever drunk an ED mixed with alcohol?"

If the question to any ED use in the past was left unanswered or if the participants were above 17 years old, the questionnaires were excluded.

Regarding statistical analysis, continuous variables are presented as means (standard deviation). Categorical variables are expressed as frequencies (percentage). Pearson's chi-square test was applied to compare proportions of categorical variables. The Student's $t$ test was used to compare differences in continuous variables. The statistical analysis was performed with SPSS ${ }^{\circledR} 19.0$
(SPSS Inc., Chicago, Illinois). All statistical tests were twosided, and a value of $p<0.05$ was taken as statistically significant.

\section{RESULTS}

We enrolled 2150 adolescents in the study. Of those, 1643 answered the questionnaire (response rate of $76.4 \%$ ) while 229 respondents were excluded based on their age or by missing ED use information. The final sample consisted of 1414 adolescents (650 males, 760 females, 4 missing data), aged between 11 and 17 years (average age 15.1 \pm 1.5 years), all attending $7^{\text {th }}$ to $12^{\text {th }}$ grade at four public schools in Braga. The data collection occurred in the classroom without any reported incident.

Most of the students $(61.7 \%)$ were senior high school students $\left(10^{\text {th }}-12^{\text {th }}\right.$ grade $), 38.3 \%$ attended junior high school $\left(7^{\text {th }}-9^{\text {th }}\right.$ grade $)$.

ED were consumed at least once in a lifetime by $56.7 \%$ of adolescents, with $34 \%$ of those reporting a regular consumption and $14.1 \%$ a weekly consumption. Table 1 describes the prevalence of "at least once" and "regular consumption", specified by gender, age and attending school year. ED consumption was more common in males $(62.5 \%$

Table 1 - Consumption of ED at least once in the lifetime and regular ED consumption (at least once a month) described by demographic subgroups $[(n), \%]$

\begin{tabular}{lcc}
\hline & Any consumption of ED & Regular ED consumption \\
\hline Male & $(406), 62.5$ & $(254), 39.1$ \\
Female & $(396), 52.1$ & $(219), 28.8$ \\
Age (Years) $\leq 13$ & $(114), 43.3$ & $(89), 33.4$ \\
Age (Years) $[14-15]$ & $(273), 53.6$ & $(182), 35.7$ \\
Age (Years) $[16-17]$ & $(416), 64.7$ & $(214), 33.3$ \\
Grade $7-9$ & $(259), 47.9$ & $(200), 36.9$ \\
Grade $10-12$ & $(541), 62.1$ & $(264), 30.3$ \\
\hline
\end{tabular}

ED: energy drinks

Table 2 - Comparative description of sociodemographic characteristic, self-reported poor academic performance, hours of sleep and BMI between ED users and non-users

\begin{tabular}{|c|c|c|c|}
\hline & ED users & ED Non-users & $p$-value \\
\hline Total (n), \% & (802), 56.7 & (612), 43.3 & NA \\
\hline Male (n), \% & (406), 62.5 & (244), 37.5 & \multirow{2}{*}{$<0.001\left(\chi^{2}\right)$} \\
\hline Female (n), \% & (396), 52.1 & $(364), 47.9$ & \\
\hline Age $\leq 13(n), \%$ & $(114), 43.3$ & (149), 56.7 & $<0.001\left(\chi^{2}\right)$ \\
\hline Age [14 - 15] (n), \% & (273), 53.6 & (236), 46.4 & $0.005\left(\chi^{2}\right)$ \\
\hline Age [16 - 17] (n), \% & (416), 64.7 & (226), 35.3 & $<0.001\left(\chi^{2}\right)$ \\
\hline Mean age (Years \pm SD) & $15.4 \pm 1.5$ & $14.8 \pm 1.6$ & $<0.001067(\mathrm{t})$ \\
\hline Grade 7 - $9(n), \%$ * & (259), 47.9 & (282), 52.1 & \multirow{2}{*}{$<0.001\left(\chi^{2}\right)$} \\
\hline Grade $10-12(n), \%$ * & (541), 62.1 & (330), 37.9 & \\
\hline Poor academic performance ${ }^{\dagger}(n), \%$ & $(96), 67.6$ & (46), 32.4 & \multirow{2}{*}{$0.005\left(\chi^{2}\right)$} \\
\hline Non-poor academic performance (n), \% & (706), 55.5 & (566), 44.5 & \\
\hline Hours of sleep (Hours \pm SD) & $8.2 \pm 1.2$ & $8.4 \pm 1.0$ & $0.015067(\mathrm{t})$ \\
\hline Mean BMI (BMI \pm SD) & $21.2 \pm 2.8$ & $21.2 \pm 13.3$ & $0.067(\mathrm{t})$ \\
\hline
\end{tabular}

ED: energy drinks; BMI: body mass index; SD: standard deviation; $\uparrow$ : self reported poor academic performance was defined by mean academic grades below 3 (in $7^{\text {th }}-9^{\text {th }}$ grades) and bellow 10 (in $10^{\text {th }}-12^{\text {th }}$ grades) or if any self-reported grade retention in the past two years; NA: not applicable; ( $\mathrm{t}$ ): $t$-student test. * $\mathrm{n}=1412$ (available data). 
of males versus $52.1 \%$ of females; $p<0.001)$ and among senior high school students $(62.1 \%$ of seniors versus $47.9 \%$ of junior students; $p<0.001$ ) (Table 2). On average, ED users were older when compared to non-users (15.4 \pm 1.5 vs $14.8 \pm 1.6$ years; $p<0.001$ ) (Table 2). When questioned about the average number of ED units consumed in a single day, most users declared drinking only one unit (87.5\%), although $5.4 \%$ of adolescent consumed three or more units.

The most commonly reported reasons for ED consumption were the pleasant taste $(49 \%)$, desire to increase global energy (35\%) and to increase sports performance $(33.0 \%$ ) (Table 3 ). About one third (32\%) of the studied individuals were aware of potential health hazards associated with ED consumption. Moreover, $30.5 \%$ of adolescents that used ED claimed to have some discomfort after consumption, with the most common complaints being acute agitation or anxiety $(36.2 \%)$ and insomnia (31.9\%) (Table 4). Concerning self-reported average sleep duration, ED consumers slept less than non-consuming students (8.2 \pm 1.2 vs $8.4 \pm 1.0$ hours, respectively; $p<$ $0.001)$ Additionally, ED consumers presented inferior self-reported academic performance $(p<0.05)$ (Table 2 ). However, $48 \%$ of participating students ignored the health consequences of sporadic ED consumption, $7 \%$ considered that ED use increases overall health status, while the remaining individuals did not express opinion on the subject. No association between ED consumption and obesity or overweight was found, and no difference in mean BMI between users and non-users was registered (Table 2). Coffee consumption was reported in $46.6 \%$ of ED users with $12.5 \%$ consuming more than one cup a day.

Overall, 311 (39.9\%) of ED consumers acknowledged previous use of AED (51\% females). Gender did not have a significant influence in the preference for combining ED with alcohol $(p=0.413)$. However, senior high students $\left(10^{\text {th }}-12^{\text {th }}\right.$ grades $)$ consumed ED together with alcohol more frequently than their younger colleagues ( $76.6 \%$ vs $20.4 \%$, respectively; $p<0.001$ ) and adolescent that mixed alcohol and ED are, in average, older than the remaining ED users $(15.9 \pm 1.3$ vs $15.0 \pm 1.5$ years, $p<0.001)$.

\section{DISCUSSION}

Consumption of ED has been growing worldwide and becoming increasingly popular between adolescents over

Table 3 - Reasons stated by the adolescents for ED consumption [(n), \%]

\begin{tabular}{lc}
\hline Reason & (n), valid \% \\
\hline Taste & $(378), 48.8$ \\
Increase energy & $(267), 34.5$ \\
Increase sportive performance & $(255), 33.0$ \\
Increase academic performance & $(91), 11.7$ \\
Decrease sleep & $(130), 16.8$ \\
Pear pressure & $(36), 4.6$ \\
Other reason & $(41), 5.2$ \\
\hline
\end{tabular}

the recent years. In our study, we found that $56.7 \%$ of the interviewed adolescents had consumed ED at least once, with $34 \%$ of those reporting regular consumption (here defined as at "least once a month"). It should be mentioned that the definition of regular consumption in the present study implies different frequencies of ED use (i.e. daily, weekly or monthly) and thus, might correspond to very different dosages of stimulants consumed.

Although the prevalence of ED consumption found in the present work is similar to that reported in the literature, the paucity of data about the same age group and the lack of standardization for the quantification of ED consumption makes it difficult to compare results. Recently, the European Food Safety Authority published a report based on a study including 16 European countries, in which the consumption of ED in adolescents was found to be of $68 \% .{ }^{21}$ Flotta D et al also found that $68 \%$ of respondent adolescents drunk ED during their life, with $55 \%$ reporting consumption in the previous 30 days. ${ }^{22}$ A German study of 1265 adolescents reported that $53 \%$ had consumed ED. ${ }^{1}$ Another survey conducted in 2013 in Canada indicated that $40 \%$ of students from grade 7 to 12 reported using ED during the previous year, with prevalence increasing with advancing school grade. ${ }^{23}$ In accordance with this report, we also found that senior students stated ED use more often than their younger colleagues. This could be due to the fact that older adolescents had been exposed to ED marketing for a larger period of time, consequently having and higher probability of previous consumption. Another explanation might be that older adolescents have easier access to ED, more disposable income and a more active nightlife than youngsters.

In the current study, ED consumption was higher among male participants compared to females. This finding is consistent with previous reports and might also be related with ED marketing approaches. , $^{911,23}$

The amount of ED units used for a day of consumption was generally lower than the one observed in other studies. In a Polish study, $12 \%$ of adolescents reported consuming 7 litres per month. An Australian study concluded that more than one third of consumers exceeded two ED units per day compared to $5.4 \%$ of the adolescents inquired in present study. ${ }^{11,24}$ However, $87.5 \%$ of those declared drinking only one ED portion, which could be an indicator of self-control

\begin{tabular}{lc} 
Table $4-$ Self-reported adverse effects of ED consumption [(n), \%] \\
\hline Symptom & (n), \% \\
\hline Agitation or anxiety & $(86), 36.2$ \\
Insomnia or trouble to sleep & $(76), 31.9$ \\
Tachycardia & $(41), 17.3$ \\
Headache & $(23), 9.6$ \\
Peripheral tremor & $(6), 2.5$ \\
Others & $(6), 2.5$ \\
\hline
\end{tabular}


in consumption.

Similar to other reports in literature, several reasons, often guided by marketing allegations, were pointed out as motivation for consuming ED. Although half of young consumers reportedly choose to consume ED based on taste alone, the other half based their decision on the expected benefits, like increase in global energy $(35 \%)$ and enhanced sports performance $(33.0 \%)$, outcomes not yet proven. For example, caffeinated beverages tend to have a dehydrating effect, making them not the best choice during exercise. ${ }^{11}$ Some of the inquired students also indicated the desire of increasing academic performance, an effect that also lacks scientific confirmation. Several studies in college student populations demonstrated a negative effect of ED use on mean academic performance. ${ }^{25,26}$ In the present study, ED consumption was associated with poorer selfreported academic performance, although a causal effect cannot be established. The cognitive short term effects caused by ED are still controversial in the adult population and it remains unclear if the effect of caffeine in adults can be generalized to adolescents. ${ }^{4,6}$

Near half of the studied individuals ignored the health consequences of sporadic ED consumption and 7\% considered that ED use increases overall health status. Furthermore, only one third were aware of potential health hazards associated with ED consumption, indicating the need for more health information about this subject, as well as educational interventions promoted at national and local level in schools.

Regarding the symptomatology often associated with ED consumption, the results found were similar to those of other studies. However, it should be emphasized that the symptoms were self-reported and as occurring after ED consumption. Therefore, a causal relationship cannot be categorically established, as other causes, such other co-consumption of other substances or previous diseases, were not evaluated. Nonetheless, a high number of consumers claimed to have some discomfort after ED consumption, like anxiety and insomnia., 3,7,11 These symptoms can occur due to caffeine intoxication or be caused by the cocktail of stimulants present in ED. After drinking a single ED unit, about $40 \%$ of teenagers exceed daily limit of caffeine consumption for their age group (100 $\mathrm{mg}){ }^{4}$ Caffeine consumption was already found to cause sleep disturbances in children and adolescents. ${ }^{19,27}$ In our results, ED users slept less than non-ED users. Yet, sleep duration and sleep quality aren't necessarily related, as a lower sleep duration doesn't automatically imply a poorer sleep quality. Future research on ED consumption and sleep problems is necessary to clarify this result. Although no life-threatening situations were reported in our results, in the literature it is possible to find descriptions about rare cases of hypertension, heart arrhythmia and death. $3,6,11$

The complete impact of ED consumption on adolescence is unknown. There are no safety requirements or restriction of ED consumption by minors. ${ }^{6}$ Risk of intoxication in children is higher compared to adults due to being in a critical phase of development and their lack of pharmacological tolerance. ${ }^{7}$ Besides ED, a high number of Portuguese students reported use other sources of caffeine, like coffee (namely $46.6 \%$ of ED users), further increasing the risk of caffeine related negative consequences and even overdose. Another relevant and common source of caffeine is the ingestion of soft drinks, a factor that was not taken into consideration in this study. ${ }^{11}$

Previous co-consumption of energy drinks and alcohol (AED) was frequent in the studied population (39.9\%), particularly in senior students, with no differences in gender. Other studies report similar results. ${ }^{11}$ Flotta $D$ et al found in his survey that $46 \%$ of Italian adolescents had drunk AED. ${ }^{22}$ Reid et al report that $76 \%$ of Canadian university students had consumed AED at least once and a quarter of students in grades 7 to 12 used AED in the preceding year. ${ }^{23}$ In 2010, the FDA labelled caffeine as an 'unsafe food additive' when added to alcoholic beverages. ${ }^{28}$ Although not assessed in our study, problems linked to AED use include higher rates of alcohol intoxication and an increase in risky behaviours. ${ }^{1,9,19,20,22}$ This fact might be related with the counteracting effect of caffeine against the sedative effects of alcohol, which leads to a reduced perception of alcohol intoxication. ${ }^{29}$ Education of parents, teachers and adolescents themselves would be an appropriate approach to control early consumption of ED or AED.

The current study has methodologic limitations that need to be addressed. The study was cross-sectional, which limits any causal inferences. Also, we did not use probability-based sample within the population studied. Thus, this study may be subject to volunteer bias, assuming that some adolescents with frequent consumption of ED might be less prone to respond the questionnaire (https:// www.actamedicaportuguesa.com/revista/index.php/amp/ article/view/9403/5411). However, we included a large number of students and had a high response rate. Also, the study sample includes only one region of Portugal, making it difficult to generalize to the entire population. For this reason, this study should be reproduced in other regions of Portugal. Self-report surveys have the potential for social desirability bias, since some items inquired about aspects of the adolescent conduct. However, the anonymity provided to all participants limited this bias. Participants self-reported previous ED consumptions without any specification of the ED brand used. As consequence, the exact amount of caffeine or other stimulants in those consumptions was unknown. Moreover, we did not fully access other types caffeine consumption (such as from soft drinks). Future research should aim to quantify more precisely ED use by inquiring about the consumed brands and exact quantities consumed. The use of standardized measures will also allow a better comparison among studies.

Further investigation is also needed to better define the effects of ED chronic use, especially in more susceptible populations, such as adolescents with pre-existing medical condition or those who consume ED in combination with alcohol. 
As far as we know, the present investigation is the first aiming to evaluate consumption of ED in a cohort of Portuguese adolescents.

\section{CONCLUSION}

Our results suggest that ED consumption is very common amongst Portuguese adolescents from Braga. Frequently containing high and unregulated amounts of psychostimulants, ED have been associated with adverse health effects and potential dangerous consequences. Prevention efforts should include regulation of ED commercialization to children and adolescents, education of general public about potential harms associated with ED and awareness promotion among medical professionals.

Unless research establishes ED safety standards in adolescents, it would be prudent to restrict its use among minors.

\section{ACKNOWLEDGEMENTS}

We would like to thank all the participants, teachers and schools for participation in this study and for allowing this publication.

\section{PROTECTION OF HUMANS AND ANIMALS}

The authors declare that the procedures were followed according to the regulations established by the Clinical Research and Ethics Committee and to the Helsinki Declaration of the World Medical Association.

\section{DATA CONFIDENTIALITY}

The authors declare having followed the protocols in use at their working center regarding patients' data publication.

\section{CONFLICTS OF INTEREST}

The authors declare no conflict of interests.

\section{FUNDING SOURCES}

This research received no specific grant from any funding agency in the public, commercial, or not-for-profit sectors.

for arrhythmias and other cardiovascular events. Can J Cardiol. 2015;31:572-5

17. Snipes DJ, Jeffers AJ, Green BA, Benotsch EG. Alcohol mixed with energy drinks are robustly associated with patterns of problematic alcohol consumption among young adult college students. Addict Behav. 2015;41:136-41.

18. Azagba S, Sharaf MF. Is alcohol mixed with energy drinks consumption associated with susceptibility to smoking? Prev Med. 2014;61:26-8.

19. Holubcikova J, Kolarcik P, Madarasova Geckova A, Joppova E, van Dijk JP, Reijneveld SA. Young adolescents who combine alcohol and energy drinks have a higher risk of reporting negative behavioural outcomes. Int J Public Health. 2017;62:379-86.

20. Emond JA, Gilbert-Diamond D, Tanski SE, Sargent JD. Energy drink consumption and the risk of alcohol use disorder among a national sample of adolescents and young adults. J Pediatr. 2014;165:1194-200.

21. European Food Safety Authority. "Energy" drinks report | European Food Safety Authority [Internet]. Energy Drinks Report. [accessed 2017 Jul 06]. Disponível em: http://www.efsa.europa.eu/en/press/news/130306.

22. Flotta D, Micò R, Nobile CGA, Pileggi C, Bianco A, Pavia M. Consumption of energy drinks, alcohol, and alcohol-mixed energy drinks among Italian adolescents. Alcohol Clin Exp Res. 2014;38:1654-61.

23. Reid JL, Hammond D, McCrory C, Dubin JA, Leatherdale ST. Use of caffeinated energy drinks among secondary school students in Ontario: Prevalence and correlates of using energy drinks and mixing with alcohol. Can J Public Health. 2015;106:e101-8.

24. Pettit ML, DeBarr KA. Perceived stress, energy drink consumption, and academic performance among college students. J Am Coll Health. 2011;59:335-41.

25. Trunzo JJ, Samter W, Morse C, McClure K, Kohn C, Volkman JE, et al. College students' use of energy drinks, social problem-solving, and academic performance. J Psychoactive Drugs. 2014;46:396-401.

26. Temple JL. Caffeine use in children: what we know, what we have left to learn, and why we should worry. Neurosci Biobehav Rev. 2009;33:793806.

27. Heatherley SV, Hancock KM, Rogers PJ. Psychostimulant and other effects of caffeine in 9- to 11-year-old children. J Child Psychol Psychiatry. 2006;47:135-42.

28. Patrick ME, Evans-Polce RJ, Maggs JL. Use of alcohol mixed with energy drinks as a predictor of alcohol-related consequences two years later. J Stud Alcohol Drugs. 2014;75:753-7.

29. Temple JL, Ziegler AM, Epstein LH. Influence of price and labeling on energy drink purchasing in an experimental convenience store. J Nutr Educ Behav. 2016;48:54-9.e1. 